\title{
A filosofia na primeira universidade da América Latina (Universidad de San Marcos 1551)
}

\author{
Alfredo Culleton *
}

Resumo: O artigo se propõe trazer a público um momento fundante da história da Filosofia nas Américas a partir do estudo da historia das Universidades e em especial a decana Universidad de San Marcos (1551), a sua fundação, funcionamento e legado. Neste contexto pretende igualmente apresentar dois notáveis intelectuais nativos que respiram o ar dessa universidade nas primeiras décadas: Jerónimo Valera e Juan de Espinosa Medrano.

Palavras-chave: Escolástica Ibero-americana; São Marcos; Universidades; Filosofia latinoamericana.

\section{Philosophy at Latin America's First University (Universidad de San Marcos} 1551)

\begin{abstract}
The article aims to bring to the public a foundational moment in the history of Philosophy in the Americas, based on the study of the history of Universities and, in particular, the dean Universidad de San Marcos (1551), its foundation, functioning and legacy. In this context, it also intends to present two notable native intellectuals who lived the atmosphere of that university in those first decades: Jerónimo Valera and Juan de Espinosa Medrano.
\end{abstract}

Key words: Ibero-American Scholasticism; San Marcos; Universities; Latin American philosophy.

\footnotetext{
* Doutor em Filosofia pela Pontifícia Universidade Católica do Rio Grande do Sul (PUCRS). Professor titular da Universidade do Vale do Rio dos Sinos (UNISINOS). E-mail: culleton@unisinos.br. ORCID: https://orcid.org/0000-0003-2036-1025. Lattes: http://lattes.cnpq.br/1692292875405642. Bolsista de Produtividade em Pesquisa do CNPq.
} 


\section{Filosofía en la Primera Universidad de América Latina (Universidad de San Marcos 1551)}

Resumen: El artículo se propone acercar al público un momento fundacional de la historia de la Filosofía en América a partir del estudio de la historia de las Universidades y en particular de la decana Universidad de San Marcos (1551), su fundación, funcionamiento y legado. En ese contexto, también pretende presentar a dos destacados intelectuales nativos que respiran el aire de esa universidad en las primeras décadas: Jerónimo Valera y Juan de Espinosa Medrano.

Palavras clave: escolástica iberoamericana; San Marcos; universidades; filosofía latinoamericana.

\section{I - Introdução}

O objetivo deste trabalho é, no âmbito do Projeto Scholastica Colonialis, dar continuidade ao estudo das fontes filosóficas de origem desenvolvidas nas Américas entre os séculos XVI e XVIII; Neste contexto, faz-se necessária a reconstrução histórica das instituições acadêmicas que o tornam possível, entre as quais priorizamos as universidades, visto que são elas que organizam e sistematizam os estudos filosóficos por excelência, mesmo quando desenvolvidos por religiosos, o que é nem sempre é o caso.

Nesse universo, é necessário saber não só quem são os autores e suas obras, mas também, para melhor compreendê-los e aproveitar melhor esses textos, para entender em que contexto histórico e conceitual esse discurso se dá. A atividade acadêmico-filosófica correspondente ao período colonial constitui um tema de pesquisa que ainda não foi realizado. A tradução e o estudo das fontes correspondentes a esta fase da nossa cultura filosófica, por estar intimamente ligada à cultura clássica grega e latina, assim como aos autores medievais, não só merece uma atenção especial mas também diz respeito ao conhecimento do nosso passado filosófico academico.

Embora fosse desejável, devido ao vasto material disponível, fazer um estudo mais completo do que indica o título da obra, neste caso não poderíamos ir muito além da reconstrução da fundação das primeiras 
universidades latinoamericanas, dando especial atenção à de San Marcos, e a dois ilustres professores que respiram a atmosfera filosófica dessas primeiras décadas da fundação, que são Jerónimo Valera e Juan de Espinosa Medrano.

\section{II - A Universidade nas Américas}

Veremos, em primeiro lugar, embora de maneira geral, as universidades que nasceram na América Latina durante o domínio espanhol, seguindo a ordem cronológica de fundação, pontifícia ou real, segundo seu documento de ereção.

No século XVI, primeiro século universitário na América, temos a Decana, a Universidade de Santo Domingo, na Ilha Espanhola (atual Santo Domingo), que nasceu pontífice em 1538, com os privilégios de Alcalá e Salamanca, e em o impulso da Ordem dos Pregadores.

As grandes, oficiais e principais de Lima e do México, no Peru e na chamada Nova Espanha, nasceram reais, com cédula real expressa em 1551. Em seguida, obtiveram a confirmação pontifícia em 1571 e 1595, respectivamente.

As outras fundações do século XVI também obtiveram documento de ereção próprio e específico: a Universidade de La Plata, Charcas ou Chuquisaca (Sucre-Bolívia), a Universidade de Santiago de La Paz, em Santo Domingo, a Tomista de Santa Fé, no Novo Reino de Granada (Bogotá-Colômbia), dos dominicanos, e de San Fulgencio (Quito-Equador), dos agostinianos. A Universidade de La Plata (1552) e a de Santiago de La $\mathrm{Paz}$ (1558) nasceram reais, ao estilo dos majores e com os privilégios de Salamanca. La Tomista (1580) e San Fulgencio (1586) surgiram como pontifícios, mas com passe real. Eram do tipo convento-universidade ou colégio-universidade, e como tal funcionava também a de Santiago de la Paz, dentro da Companhia de Jesus.

O século XVII se destaca pela quantidade do tipo conventual ou colégio-universitário: o de Nuestra Señora del Rosario (1619), no convento 
dominicano de Santiago do Chile; e da Companhia de Jesus, com privilégios gerais de graduação, os seguintes: La Javeriana de Santa Fé (1621), La de Córdoba (1621), San Francisco Xavier de Charcas ou Chuquisaca (1621), San Miguel em Santiago do Chile ( 1621), San Gregorio Magno em Quito (1621), e o de Mérida de Yucatán (1621-22); Tudo pontifício, mas com um placet real. Seguindo este modelo estão Santo Tomás de Quito (1681), San Antonio Abad de Cuzco (1683) e San Nicolás, dos agostinianos em Santa Fé (1694); de caráter estritamente real, e com posterior reconhecimento pontifício: os de San Carlos de Guatemala (real em 1676 e pontifício em 1687) e o de San Cristóbal de Huamanga (Ayacucho-Peru) (real em 1680 pontifício em 1682)

Em 1600 já existiam mais de 20 universidades, com reconhecimento real e pontifício, e com os mesmos privilégios de Salamanca e Alcalá, não apenas para conceder graus (bacharelado, graduação, mestre e doutor), mas relativo à autonomia e direitos de gestão, e privilégios dos graduados egressos, bem como bibliotecas que nada deixavam a desejar às suas universidades de origem.

As Universidades de Havana, Caracas, Santiago do Chile, Buenos Aires, San Francisco Javier de Panamá, San José de Nueva Granada, Concepción de Chile, Asunción del Paraguay, Guadalajara, são do século 18 e não têm mais Salamanca e Alcalá como um modelo, mas San Marcos. Como esta é a Decana das Américas, faremos uma breve reconstrução de sua identidade.

\section{III - A universidade de San Marcos}

No Capítulo Provincial da Ordem de Santo Domingo, realizado em Cuzco em julho de 1548, Frei Tomás de San Martín levantou a necessidade de fundar um Studium generale em Lima. O capítulo concordou em iniciálo nos claustros do convento de Santo Domingo da referida cidade e elegeu em 10 de dezembro de 1549 Frei Tomás de San Martín e ao Capitão Jerónimo de Aliaga, procuradores na corte de Madrid; de modo que 
solicitaram ao Monarca a criação deste studium que deveria funcionar no referido convento. Com este acordo e disposição comunal passou a funcionar, e é aí que alguns autores consideraram como a data da fundação da Universidade de Lima o ano de 1549.

Por Real Cédula concedido em Valladolid em 12 de maio de 1551 Carlos I da Espanha e V da Alemanha estende a Cédula de Fundação do Estudo Geral e da Universidade de Lima no convento de Santo Domingo, com o nome de Real e Pontifícia Universidade de Lima e desta maneira fica estabelecida a primeira das universidades no continente americano.

Em 1552, o Capítulo Provincial da Ordem de Santo Domingo de Lima acordou a criação das Cátedras de Gramática; Retórica, Artes; Teologia; Língua latina e quíchua; se designou Regente de Estudos ao Padre Rafael Segura, Catedrático de Prima Teologia.

Em 2 de janeiro de 1553, este Studium generale foi inaugurado na casa capitular do Convento do Rosário. A Universidade, que deveria ser o principal centro de cultura do vice-reino peruano, foi assim legitimamente constituída, portadora da verdade, da civilização e do progresso. O primeiro Reitor foi Fray Juan de la Roca, Prior da Ordem de Santo Domingo. Nos primeiros anos, a Universidade se adaptou às características da época em que foi fundada. A Universidade começou suas atividades com recursos limitados. Assim, os primeiros mestres, da Ordem dos Pregadores, colaboram sem cobrar qualquer remuneração por seus serviços. O desenvolvimento dos estudos obedeceu aos padrões universitários da metrópole, especificamente de Salamanca. Se começava com filosofia na Faculdade de Letras, como propedêutica para qualquer carreira. As principais faculdades que funcionaram foram Teologia e Direito Canônico. A universidade outorgava os graus de Bacharel, Licenciado, assim como Doutor e Mestre. Quanto ao governo e à administração universitária, eram dirigidos pelo reitor, quatro consiliarios (dois doutores antigos e dois bacharéis recém-formados), um secretário, um encarregado mor ou tesoureiro e dois zeladores encarregados do funcionamento disciplinar da Universidade. Para resolver as questões mais importantes, se reunia o claustro, formado pelos catedráticos e graduados de San Marcos, embora 
não exercessem a docência. Nas etapas pelas quais passou a Universidade, no período que vai de 1553 a 1571, os reitores foram, ao mesmo tempo, os priores da Ordem Dominicana. Muito em breve o Studium generale começaria a servir de cenário de luta entre doutores leigos e catedráticos religiosos.

Os estudos durante os primeiros anos não sofrem interrupções nem dificuldades maiores. A partir de 1564 surgiu um movimento para pedir ao Rei a retirada da universidade do convento de Santo Domingo, que até então tinha um caráter semelhante a Salamanca onde predominava o pensamento mais aberto de Santo Tomás de Aquino, onde os primeiros criollos (filhos de Ibéricos e naturais das Américas) começam a formação nas Artes Liberais.

Em 11 de maio de 1571, a Real Audiência autorizou os doutores e mestres da Universidade, a seu pedido, a escolher livremente um reitor e, após a votação, resulta eleito o Doutor Pedro Fernández de Valenzuela; prefeito de Corte e Crime do Tribunal Real. A Ordem de Santo Domingo solicitou a nulidade desta eleição e pela força foi impedida a realização de atos universitários nos claustros; Por isso, a Audiência por decisão de 25 de julho do mesmo ano ordenou que, temporariamente, fossem celebradas na Catedral; pela Bula do Papa Pio V, de 15 de julho de 1571, foi confirmada a fundação da Universidade de Lima; com os mesmos privilégios dos de Salamanca e acrescentando ao seu ditado da Universidade Real o de Pontifícia.

O primeiro Reitor secular foi Pedro Fernández de Valenzuela; apresentou as primeiras Constituições e Estatutos em 11 de outubro de 1571. Por decreto real emitido em Madrid em 30 de dezembro do mesmo ano, o Rei Felipe II aprovou as disposições do Vice-Rei, a Real Audiência de Lima, a respeito do Reitorado da Universidade e dispôs que ocupasse um lugar independente e próprio fora do Convento. 


\section{IV - Vice-rei Toledo e a secularização da Universidade de San Marcos}

Quando Francisco de Toledo, quinto vice-rei do Peru, chegou a Lima, teve que enfrentar os novos problemas que surgiram e, pensando que a ordem colonial deveria nascer da observância das necessidades dos indígenas e dos espanhóis, quis conhecê-los pessoalmente e iniciar uma viagem pelas terras do vice-reinado, que durou cinco anos. Seu esforço tenaz traduziu-o nas Ordenanças ${ }^{1}$. Ao vice-rei Toledo deve a Universidade sua autonomia e sustentabilidade econômica. Por isso, no decorrer dos anos coloniais, a Universidade sempre viu no nome de Toledo "o esforço criativo e a inteligência voltada para o futuro". O seu trabalho "haveria de imprimir uma marca muito profunda na história de Lima ... Reorganizou a Universidade e dotou-a de rendimentos e de leis, sendo o tutor do direito universitário de Lima, com base na tradição de Salamanca." Ele teve o cuidado de aumentar os estudos de San Marcos. As cadeiras de Gramática e Língua Indígena foram instituídas; três de Filosofia; um da Sagrada Escritura; três das Leis e duas de Cânones.

No período de 1553 a 1571 o número de estudantes foi aumentando e foram ingressando "frades de outras Ordens, clérigos e leigos de diferentes profissões, em particular juristas, médicos e mestres em artes. Começa então a predominar um outro ponto de vista diferente àquele dos dominicanos, fato que acabaria por desencadear divergências e a primeira reforma universitária "2. Em Segóvia, em 19 de outubro de 1565, o rei assinou um decreto real ordenando ao presidente da audiência real e aos auditores que abrisse uma investigação sobre a situação da Universidade, se deveria ser feita uma nova e em que lugar. Toledo não desconhecia as denúncias internas da universidade e se posiciona ao lado dos que lutam pela sua independência, entre eles: o arcebispo, o conselho e a audiência. Expõe ao Rei a comodidade de fundar uma Universidade autonoma, com prédio

\footnotetext{
${ }^{1}$ RODRIGUEZ CRUZ, A. Salmantica docet. La proyección de la Universidad de Salamanca en Hispanoamérica. Salamanca, Universidad de Salamanca, 1977, p. 204.

${ }^{2}$ Idem., p. 207.
} 
próprio. Em Auto, de 11 de maio de 1571, a audiência autorizou o claustro da universidade a proceder à eleição de reitor leigo. No dia 21 de junho do mesmo ano, o público ratificou novamente a ordem, exigindo que em caso de dificuldade os diplomas fossem dados na igreja catedral. Membros do claustro da Ordem Dominicana também foram convocados ${ }^{3}$.

Desde 1574 já está registado o seu funcionamento no antigo convento de San Agustín, onde inicia a sua vida independente a partir da Ordem dos Pregadores e com instalações próprias, nas quais foi sorteado o nome do seu patrono, San Marcos. Em 1576 mudou-se para o edifício San Juan de la Penitência, local cedido pelo vice-rei Toledo, e onde se radicou por mais tempo, até o final do período hispânico e início do período republicano. Na segunda metade do século XIX foi transferido para o antigo Convictorium de San Garios, onde celebrou seu quarto centenário. Nessa época, teve início a construção da cidade universitária, na Avenida Venezuela, onde hoje funciona ${ }^{4}$. Reunido em pleno claustro e em escrutínio secreto, foi eleito reitor o Dr. Pedro Fernández de Valenzuela. Os frades foram assim eliminados do cargo de reitor. A partir de 1581, a alternativa anual entre clérigos e leigos foi aprovada. O reitor pode ser reeleito pelo claustro. Para um terceiro mandato anual, era necessária a ratificação do vice-rei, na qualidade de vice-patrono da Universidade. Durante a gestão do primeiro reitor secular, as constituições e portarias da Universidade foram aprovadas em 11 de outubro de 1571, por ordem do vice-rei Toledo (anteriormente era regida pela "ratio studiorum da Ordem dos Pregadores"), consistiam em 43 estatutos, neles se via a pegada de Salamanca: as

${ }^{3}$ EGUIGUREN, L. A.: Historia de la Universidad. Lima, Universidad Nacional Mayor de San Marcos, 1951, p. 170. RODRIGUEZ CRUZ, A.: Op. cit.. p. 205. Consúltese también a Barreda Laos, F.: Vida intelectual del Virreinato del Perú. Lima, Universidad Nacional Mayor de San Marcos, 1964 y VALCARCEL, D., San Marcos. Universidad Decana de América. Lima, 1968, p. 22.

${ }^{4}$ Cf. EGUIGUREN, L. A. Historia de la Universidad, t. I, 1951, p. 86; RODRIGUEZ CRUZ, A. Historia de las Universidades Hispanoamericanas. Bogotá, Patronato Colombiano de Artes y Ciencias e Instituto Caro y Cuervo, 1972, t. I, p. 199. Consúltese especialmente a VALCARCEL, D., El actual edificio de la Universidad Nacional Mayor de San Marcos. Lima, 1951. P. 189. 
Constituições de Martinho V, base de toda a legislação universitária de Salamanca, e os Estatutos de 1538, com as reformas de Covarrubias de 1561. Era uma Salamanca em miniatura. Essas constituições foram aperfeiçoadas e ampliadas por Toledo, que promulgou as reformadas em 23 de janeiro de 1578, e que serviriam de base para as subsequentes promulgadas em 22 de abril de 1581, não impressas até 1602. Estas últimas foram elaboradas na ocasião da visita que Toledo mandou fazer de dois membros do claustro, Frei Pedro Gutiérrez Flores, da ordem de Alcántara, e reitor de meados de 1580 a 1581, e o Dr. Diego de Zúñiga, prefeito do crime. Estas constituições foram os que governaram a vida acadêmica por mais vez, durante o resto do período hispânico, com ligeiras edições posteriores.

Data de registro: $16 / 09 / 2021$

Data de aceite: 20/12/2021 